\title{
Site of Conversion of Carotene to Vitamin A
}

By S. K. Kon and S. Y. Thompson, National Institute for Research in Dairying, University of Reading

The liver has for a long time been considered as the main site of metabolic activity and it seemed natural that, when Moore (1930) demonstrated that carotene is converted in the animal body to vitamin A which is then stored in the liver, he assumed (Moore, 1931) that it is in the liver that conversion takes place. This view was generally held for the next 15 years though the supporting experimental evidence, ably summarized by Glover, Goodwin \& Morton (1948b), was neither satisfactory nor conclusive.

The almost complete absence of carotenoids, even after a carotene meal, from the blood of some animals, notably the rat, the pig, the sheep and the goat, provided an important objection to the hepatic theory, since it failed to explain how in such animals the carotene taken up by the intestine would reach the liver. The possibility of a brief travel through the portal vein followed by an immediate and quantitative removal by the liver was discounted by the experiments of Goodwin, Dewar \& Gregory (1946) and of Goodwin \& Gregory (1948) who failed to detect carotene in the portal or systemic blood of rabbits, goats and sheep after administration of massive doses in various forms by mouth or directly into the true stomach or the duodenum, yet vitamin A similarly given appeared in the blood in large quantities.

Attempts to produce experimental proof turned mainly on the value of carotene when given parenterally, since the demonstration of its activity under such conditions would go far in support of the hepatic theory of conversion. The findings were conflicting and most of the experiments open to criticism (cf. Glover et al., 1948b). More recently, however, Sexton, Mehl \& Deuel (1946) produced clear-cut evidence that carotene introduced parenterally into vitamin A-deficient rats was not only not converted but accumulated in the liver without relieving the symptoms of deficiency. From these experiments Sexton $e t$ al. concluded that 'a possible site for the transformation of carotene to vitamin A might be in the intestinal wall'. This possibility had also occurred to some earlier observers. Thus Verzár \& McDougall (1936) commented as follows on remarkable experiments from Drummond's laboratory: 'Drummond, Bell and Palmer (1935) have recently described in a patient with chylothorax the path of absorption of carotene and vitamin A....Vitamin A was given as the free alcohol. During the passage through the intestinal wall all the vitamin A was esterified with fatty acids. Whether the carotene was also already transformed to vitamin $A$ in the mucosa -as one might suppose-was not studied.' Nearly ro years ago Popper \& Greenberg (1941) observed by fluorescence microscopy the appearance of vitamin $A$ in different sites of depleted rats and reported: "The first fluorescence after feeding of carotene was seen in the intestine or in the Kupffer cells and then in the adjacent parts of the liver cells or in the endothelial cells of the renal cortex and lung or in the adrenal cortex....Probably carotene is converted into vitamin A in one or all of these locations.'

'The finding that the intestine of fish contained vitamin $A$ in very high concentration (Edisbury, Morton, Simpkins \& Lovern, 1938; Lovern, Morton \& Ireland, 1939; 
Lovern, Mead \& Morton, 1939) and localized in the mucosa (Lovern \& Morton, 1939) further emphasized the possible importance of this organ in the metabolism of the vitamin.

\section{The intestine as site of conversion}

Finally evidence for the intestinal conversion of carotene in higher vertebrates came independently and almost simultaneously from three different laboratories (Glover et al. 1947; Mattson, Mehl \& Deuel, I947; Wiese, Mehl \& Deuel, 1947; Thompson, Ganguly \& Kon, 1947). The preliminary reports from Liverpool and Shinfield were followed by full publications (Goodwin \& Gregory, 1948; Glover et al. $1948 b$; Thompson, Ganguly \& Kon, 1949). Further evidence came thence (Thompson, Braude, Cowie, Ganguly \& Kon, 1949; Thompson, Coates \& Kon, 1950; Coates, Thompson \& Kon, 1950; Thompson, Braude, Coates, Cowie, Ganguly \& Kon, 1950; Alexander \& Goodwin, 1950) and from the Californian laboratory (Mattson, I948; Cheng \& Deuel, 1950). These original observations are supported by those obtained elsewhere (McCoord \& Clausen, 1948; Krause \& Pierce, I948; Elliot, 1949; Klosterman, Bolin \& Light, 1949; Swick, Grummer \& Baumann, 1949; Stallcup \& Herman, 1950).

However strongly this large body of evidence supports the intestine as the organ where conversion takes place, the evidence against the liver as another, or for that matter the only, active site is still only indirect. As far as we know all experiments but one with living animals were performed on those with unimpaired liver circulation, and in none was the liver removed. Even the valuable study of Krause \& Pierce (1948), in which the hepatic circulation was blocked, cannot, on their own admission, be taken to settle the point. Likewise the decision does not rest with experiments in vitro, valuable though they may be, since the synthetic activity of the dead intestine or of intestinal tissues is not a determining guide to the chain of events in the living body.

The proof is based on the appearance of vitamin A outside the liver after a meal of carotene under conditions making it clear that it originated in the small intestine. Though overwhelmingly strong, the proof springs not from one crucial experiment, but derives from the sum-total of evidence. We think it more prudent, therefore, to treat it as circumstantial and to consider in reasonable sequence its component links. This summing up need be only brief, since more detailed discussion of most points will be found in the original papers, and especially in the two full reports from our laboratory published in this journal.

\section{Validity of analytical methods used}

As far as we are aware, the vitamin A appearing outside the liver, in the intestine or in the lymph flowing from it, has been identified only by chemical or physical means and biological proof is not yet available. However, in several instances the measurements either by the antimony-trichloride test (Glover et al. 1948b; Thompson, Ganguly \& Kon, 1949; Thompson, Braude, Coates, Cowie, Ganguly \& Kon, 1950) or by absorption in the ultraviolet (Glover et al. 1948b; Mattson, 1948; Thompson, Braude, Coates, Cowie, Ganguly $\&$ Kon, 1950) were preceded by careful chromatographic purification and the spectral absorption curve proved identical with that of vitamin A. Moreover, 
the characteristic fluorescence in the ultraviolet was also observed (Mattson, r948; Thompson, Ganguly \& Kon, I949; Thompson, Braude, Coates, Cowie, Ganguly \& Kon, 1950); it was identical in a mixed chromatogram with that of vitamin A (Mattson, 1948).

\section{Absence of stored vitamin $A$ from intestine; appearance after meal of carotene}

Experiments with rats (Mattson et al. 1947; Glover et al. 1948b; Thompson, Ganguly \& Kon, 1949), chicks (Cheng \& Deuel, 1950) and lambs (Klosterman et al. 1949) have shown that the intestine is not a storage place for vitamin $A$, and that it can be depleted of it in a few days in animals with large liver reserves. After a meal of carotene vitamin A promptly appeared in the small intestine of such animals and also of deficient rats (Mattson et al. 1947; Glover et al. 1948b; Thompson, Ganguly \& Kon, 1949; Thompson, Braude, Coates, Cowie, Ganguly \& Kon, I950) and chicks (Thompson, Coates \& Kon, 1950; Cheng \& Deuel, 1950) but not in the stomach or large intestine (Glover et al. $1948 b$; Thompson, Ganguly \& Kon, 1949). In the rat the peak of concentration was just proximal to the middle of the small intestine irrespective of the time interval between dosing and killing, whereas for carotene the peak shifted towards the large intestine with progress of time. The vitamin did not appear in that part of the intestine preceding the entrance of the common bile duct (Thompson, Ganguly \& Kon, 1949; Thompson, Braude, Coates, Cowie, Ganguly \& Kon, 1950).

\section{Time relationships after a carotene meal}

In all these experiments with deficient rats and chicks the appearance of vitamin $\mathrm{A}$ in the small intestine preceded that in any other site, and for a time exceeded the accumulation in the liver. Thus in our experience under favourable conditions vitamin A may appear in the intestine of previously depleted rats within $5 \mathrm{~min}$. of their receiving carotene in colloidal or oily solution (Thompson, Braude, Coates, Cowie, Ganguly \& Kon, 1950), yet never in numerous instances did we detect it in increased quantities in the blood or in the liver less than $\mathrm{I} \mathrm{hr}$. after the carotene meal. In the rat, only after $2 \mathrm{hr}$. the steady accumulation in the liver began to outstrip in quantity that found in the intestine (Thompson, Ganguly \& Kon, 1949). In the chick this time lag was even more striking (Thompson, Coates \& Kon, 1950; Cheng \& Deuel, 1950).

\section{Behaviour in the intestine of carotene, retinene and vitamin $A$ alcohol and ester}

Whether carotene, retinene (vitamin A aldehyde), or free or esterified vitamin A was given it was largely the ester form of vitamin $A$ that appeared in the intestine, and in all instances the site of maximal concentration was the same (Glover et al. 1948a; 'Thompson, Ganguly \& Kon, 1949; Thompson, Braude, Coates, Cowie, Ganguly \& Kon, 1950). According to Glover et al. (1948a) vitamin A aldehyde is the first step in the transformation of carotene to vitamin $A$ in vivo, and this view is supported by the remarkable oxidative fission of $\beta$-carotene to retinene by manganese dioxide recently reported by Meunier, Jouanneteau \& Zwingelstein (1950).

Most, if not all, of the vitamin A appearing in the intestine is concentrated in the 
wall (Mattson et al. 1947; Glover et al. 1948b; Thompson, Braude, Coates, Cowie, Ganguly \& Kon, 1950). The earlier finding of appreciable quantities in the content by 'Thompson, Ganguly \& Kon (1949) was due to a faulty technique.

\section{Blood relationships after a carotene meal}

We have already mentioned that Goodwin \& Gregory (1948) failed to detect carotene in the portal or systemic blood of rabbits, goats and sheep after massive doses of carotene. The same is true for the pig (Thompson, Braude, Coates, Cowie, Ganguly \& Kon, 1950) and was observed for the systemic blood of the rat by all those who used this animal. Moreover, observations with the rat ('Thompson, Ganguly \& Kon, 1949) and the pig (Thompson, Braude, Coates, Cowie, Ganguly \& Kon, 1950) indicated that, in these animals at least, after a meal of carotene an increase in vitamin A ester preceded in the blood an increase in vitamin A alcohol. Since, normally, vitamin A alcohol as the circulatory form predominates in the blood, it seems reasonable to assume that the ester is on its way to the liver, its main storage place, from the intestine, where it was formed.

In the observations just mentioned with the pig the ester appeared simultaneously in the portal and systemic circulations, making it unlikely that it had gone directly into the portal route. The experience of Frazer (1946, 1948) with fat, and of Drummond et al. (1935), Popper \& Volk (1944), Eden \& Sellers (I948), Goodwin \& Gregory (1948) and Thompson, Ganguly \& Kon (1949), suggests that the transport occurs largely through the lymphatics. Experiments with lymph support this view.

\section{Study of lymph}

Examination of thoracic, and to an even greater extent of mesenteric, lymph has thrown much light on the problem of intestinal conversion of carotene. Cannulation of the thoracic duct in goats (Goodwin \& Gregory, 1948) and of a mesenteric lymphatic in pigs (Thompson, Braude, Coates, Cowie, Ganguly \& Kon, 1950) demonstrated the appearance in both sites after a meal of carotene of vitamin A, exclusively as ester, and in the pig the extent of the increase was remarkable. Alexander \& Goodwin (1950) and Thompson, Braude, Coates, Cowie, Ganguly \& Kon (1950) obtained similar results with the rat, and perhaps the experiments of the latter authors may be taken as yielding the most convincing proof, since they showed that by tapping and removing the lymph flowing from the intestine vitamin $A$ was prevented from reaching the blood or the liver.

\section{Blocking of liver circulation}

In an important experiment Krause \& Pierce (1948) ligated in the rat in a two-stage operation the portal vein, the hepatic artery and the common bile duct. The vitamin A content of the serum of such rats rose after a meal of carotene to an extent comparable with that observed with normal rats.

In vitro tests

In vitro tests have consisted mainly of incubation of intestines with carotene. It cannot be said that the findings are convincing. Though Wiese et al. (1948) and Glover 
et al. (I948b) reported some formation of vitamin A under such conditions, the latter doubt the significance of their findings. Stallcup \& Herman (1950) report positive results with calf intestine but even better efficiency with minced liver tissue.

We have so far failed in unpublished experiments done in collaboration with Drs Fisher and Parsons of Oxford to effect conversion of carotene by perfusion of surviving rat intestine by their technique (Fisher $\&$ Parsons, 1949-50).

\section{Observations with several species of animals}

The number of species that contributed to the evidence for intestinal conversion is already impressive. Work with rats, pigs, goats, rabbits, sheep and chicks has already been discussed. Elliott (1949) mentions briefly work with calves, and Klosterman et al. (1949) reported further expcriments on sheep and Swick et al. (1949) on pigs.

Already 12 years ago Wagner (1939) claimed to have observed conversion of carotene to vitamin $A$ in the intestine of baleen whales. Though we do not deny that whales possess this capacity we doubt whether they ever have the opportunity since, contrary to Wagner's statements, their food contains no carotene, but appreciable quantities of preformed vitamin A (Thompson, Ganguly \& Kon, r949; Kon \& Thompson, 1949a, $b$; Batham, Fisher, Henry, Kon \& Thompson, r95I).

\section{The intestine as a metabolic site}

The recent demonstration by Popják \& Beeckmans ( 1950 ) that synthesis of cholesterol and of fatty acids takes place in the intestine adds force to the proof of intestinal conversion of carotene. In fact, its large surface and rich blood supply make it likely that the intestine is a seat of metabolic activity comparable with the liver.

\section{Conclusion}

It seems to us that on the basis of the evidence presented the conclusion is inevitable that $\beta$-carotene is transformed in the intestinal wall to vitamin A ester (probably through retinene) and that it is carried thence by the lymphatics to the blood stream and finally to the liver.

\section{REFERENCES}

Alexander, J. \& Goodwin, T. W. (1950). Brit. F. Nutrit. 4, 42 I.

Batham, E., Fisher, L. R., Henry, K. M., Kon, S. K. \& Thompson, S. Y. (1951). Biochem. $7.48, x$.

Cheng, A. L. S. \& Deuel, H. J. Jr. (1950). F. Nutrit. 4I, 619.

Coates, M. E., Thompson, S. Y. \& Kon, S. K. (1950). Biochem. F. 46, xxx.

Drummond, J. C., Bell, M. E. \& Palmer, E. T. (1935). Brit. med. F. i, 1208.

Eden, E. \& Sellers, K. C. (1948). Biochem. F. 42, xlix.

Edisbury, J. R., Morton, R. A., Simpkins, G. W. \& Lovern, J. A. (1938). Biochem. F. 32, I 8.

Elliott, R. F. (1949). F. Dairy Sci. 32, 7 I r.

Fisher, R. B. \& Parsons, D. S. (1949-50). J. Physiol. 110, 36.

Frazer, A. C. (1946). Physiol. Rev. 26, 103.

Frazer, A. C. (1948). Arch. Sci. Physiol. 2, 15.

Glover, J., Goodwin, 'T. W. \& Morton, R. A. (1947). Biochem. J. 41, xlv.

Glover, J., Goodwin, T. W. \& Morton, R. A. (1948a). Biochem. F. 43, 109.

Glover, J., Goodwin, T. W. \& Morton, R. A. (1948b). Biochem. F. 43, 512.

Goodwin, T. W., Dewar, A. D. \& Gregory, R. A. (1946). Biochem. F. 40, Ix.

Goodwin, T. W. \& Gregory, R. A. (1948). Biochem. F. 43, 505.

Klosterman, E. W., Bolin, D. W. \& I,ight, M. R. (1949). Ұ. Anim. Sci. 8, 624.

Kon, S. K. \& Thompson, S. Y. (1949a). Biochem. F. 45, xxi. 
Kon, S. K. \& Thompson, S. Y. (1949b). Arch. Biochem. $24,233$.

Krause, R. F. \& Pierce, H. B. (1948). Arch. Biochem. 19, 145.

Lovern, J. A., Mead, T. H. \& Morton, R. A. (1939). Biochem. F. 33, 338.

Lovern, J. A. \& Morton, R. A. (1939). Biochem. F. 33, 330.

Lovern, J. A., Morton, R. A. \& Ireland, J. (1939). Biochem. F. 33, 325.

McCoord, A. B. \& Clausen, S. W. (1948). Abstr. Pap. Amer. Chem. Soc. I14th Mtg, p. I6c.

Mattson, F. H. (1948). J. biol. Chem. 176, 1467.

Mattson, F. H., Mehl, J. W. \& Deuel, H. J. Jr. (1947). Arch. Biochem. 15, 65.

Meunier, P., Jouanneteau, J. \& Zwingelstein, G. (1950). C.R. Acad. Sci., Paris, 231, I 170.

Moore, T. (1930). Biochem. F. 24, 692.

Moore, T. (1931). Biochem. J. 25, 275.

Popják, G. \& Beeckmans, M. L. (1950). Biochem. F. 47, 233.

Popper, H. \& Greenberg, R. (1941). Arch. Path. 32, 11.

Popper, H. \& Volk, B. W. (1944). Arch. Path. 38. 71 .

Sexton, E. L., Mehl, J. W. \& Deuel, H. J. Jr. (1946). F. Nutrit. 31, 299.

Stallcup, O. T. \& Herman, H. A. (1950). F. Dairy Sci. 33, 237.

Swick, R. W., Grummer, R. H. \& Baumann, C. A. (r 949). F. Anim. Sci. 8, 645.

Thompson, S. Y., Braude, R., Coates, M. E., Cowie, A. T., Ganguly, J. \& Kon, S. K. (1950). Brit. F. Nutrit. 4, 398.

Thompson, S. Y., Braude, R., Cowie, A. T., Ganguly, J. \& Kon, S. K. (1949). Biochem. F. 44, ix.

'Thompson, S. Y., Coates, M. E. \& Kon, S. K. (1950). Biochem. Y. 46, xox.

Thompson, S. Y., Ganguly, J. \& Kon, S. K. (1947). Brit. F. Nutrit. I, v.

Thompson, S. Y., Ganguly, J. \& Kon, S. K. (1949). Brit. F. Nutrit. 3, 50.

Verzár, F. \& McDougall, E. J. (1936). Absorption from the Intestine, p. 222. London: Longmans, Green and $\mathrm{Co}$.

Wagner, K. H.(1939). Vitamin A und B-Carotin des Fin-, Blau-und Spermwals. Leipzig:Johann Ambrosius Barth.

Wiese, C. E., Mehl, J. W. \& Deuel, H. J. Jr. (1947). Arch. Biochem. 15, 75.

\section{Vitamin A Levels in Health and Disease}

\section{By T. Moore and I. M. Sharman, Dunn Nutritional Laboratory, University of Cambridge and Medical Research Council}

The antimony-trichloride method for estimating vitamin A has now been available for nearly 25 years, and has been used to study the metabolism of the vitamin in man and animals by numerous workers all over the world. It is not surprising, therefore, that the wealth of literature is quite beyond compression into a short review, so that we cannot hope to outline more than a few of the main developments in the field, with emphasis on points in which we have been personally interested.

The levels of vitamin $A$ in the blood plasma and tissues are influenced by numerous factors, including the rate of intake of vitamin A or carotene, the efficiency of absorption from the intestines, the storage of vitamin $\mathrm{A}$ in the liver and other tissues, its mobilization from the liver into the blood plasma, and its removal from the plasma by transfer to the tissues, by destruction, and sometimes by urinary excretion. The various stages in the absorption, mobilization and utilization of the vitamin, however, probably overlap considerably. Thus, it must not be concluded that the vitamin invariably passes through the liver before being transferred to other tissues.

\section{Absorption}

Preformed vitamin A is generally much more efficiently absorbed than carotene, although the disparity decreases, and possibly eventually disappears, at low levels of dosing. Numerous investigations have been made on the effect of massive doses of 